\title{
Use of Limestone Fines to Reduce Permeability of Concrete for Durability Improvement
}

\author{
J. J. Chen ${ }^{1, ~ *}$, P. L. $\mathrm{Ng}^{2,3}$, L. G. $\mathrm{Li}^{4}$, A. K. H. Kwan ${ }^{3}$ \\ ${ }^{1}$ Department of Civil Engineering, Foshan University, Foshan, China \\ ${ }^{2}$ Faculty of Civil Engineering, Vilnius Gediminas Technical University, Vilnius, Lithuania \\ ${ }^{3}$ Department of Civil Engineering, the University of Hong Kong, Hong Kong, China \\ ${ }^{4}$ Department of Civil Engineering, Guangdong University of Technology, Guangzhou, China
}

Email address:

chen.jiajian@yahoo.com.hk (J. J. Chen), irdngpl@gmail.com (P. L. Ng), ligu123@msn.com (L. G. Li), khkwan@hku.hk (A. K. H. Kwan) ${ }^{*}$ Corresponding author

\section{To cite this article:}

J. J. Chen, P. L. Ng, L. G. Li, A. K. H. Kwan. Use of Limestone Fines to Reduce Permeability of Concrete for Durability Improvement. American Journal of Civil Engineering. Vol. 4, No. 4, 2016, pp. 185-190. doi: 10.11648/j.ajce.20160404.18

Received: May 30, 2016; Accepted: June 20, 2016; Published: June 30, 2016

\begin{abstract}
Traditionally, the use of limestone fines (LF) in concrete is to replace either part of the cement or part of the fine aggregate, notwithstanding this, the authors are advocating that the LF should be better used as cement paste replacement, which is expected to improve the durability and sustainability of concrete at the same time. To verify this new strategy of using LF, 9 nos. concrete mixes of the same powder paste volume ratio and variable LF contents and W/C ratios were produced for permeability and strength measurement. The results proved that the strategy of using LF to partially replace cement paste could effectively decrease the permeability and increase the strength at the same W/C ratio. Furthermore, even when the W/C ratio is allowed to slightly increase while keeping the concrete at the same strength, the permeability can also be significantly reduced for better durability by using LF as cement paste replacement.
\end{abstract}

Keywords: Durability, Limestone Fines, Permeability

\section{Introduction}

In the past, the usage of limestone fines (LF) in concrete production was by adding LF to replace either part of the cement or part of the fine aggregate [1-9]. In this regard, the authors advocate that the inert LF filler with particle size similar to or slightly larger than cement grains should better be used to fill into the voids between the aggregate particles so as to improve the packing density of the aggregate and reduce the volume of voids to be filled by the cement paste. The voids between the aggregate particles must be completely filled with cement paste or otherwise air would be entrapped in the concrete mix causing reductions in strength and durability. By adding LF to fill into the voids between the aggregate particles, the volume of cement paste needed to fill the voids would be reduced. Hence, the use of LF could replace part of the cement paste in concrete.

The cement paste volume together with the LF volume is called the powder paste volume. The powder paste volume must be sufficient to fill up the voids between the aggregate particles. With LF added, the cement paste volume can be effectively reduced by an amount equal to the LF volume. This is equivalent to adding LF to replace an equal volume of cement paste. Due to the much lower energy and carbon footprints of LF as compared to cement which requires heating up to high temperature to form clinker, the use of LF in concrete production can result in more environmentally friendly and sustainable concrete.

So far, there is little research on the possible effects of adding LF as cement paste replacement on the durability performance of concrete. As for the addition of LF as fine aggregate replacement, the addition of LF as cement paste replacement would increase the amount of fine particles in the concrete mix because the volume of LF added is larger than the volume of cement replaced. In theory, this should reduce the average pore size of the voids between the aggregate particles and reduce the water permeability of concrete. Hence, it is anticipated that the addition of LF as cement paste 
replacement would also improve the durability performance of the concrete produced. Moreover, it is the authors' belief that the above strategy of adding LF can improve the packing density of the aggregate, reduce the cement consumption without causing reduction in strength, and improve the sustainability of concrete. It is expected that the incorporation of LF could effectively reduce the permeability at the same strength. To verify this, an experimental program aiming to evaluate the effects of adding LF as cement paste replacement on the permeability of concrete has been conducted, as reported hereunder.

\section{Materials}

An ordinary Portland cement (OPC) of strength class $52.5 \mathrm{~N}$ complying with British Standard BS 12: 1996 [10] (equivalent to ASTM Type I) and a finely ground LF were used in all the concrete mixes. The 28-day mortar cube strength of the OPC was measured as $59.0 \mathrm{MPa}$, whereas the specific gravities of the OPC and LF were measured as 3.11 and 2.64, respectively. By using a laser particle size analyzer, the volumetric mean particle sizes of the OPC and LF were determined as $11.4 \mu \mathrm{m}$ and $14.5 \mu \mathrm{m}$, respectively.

Both the coarse and fine aggregates were obtained from crushed granite rock. They were procured from the market and were thus representative of typical aggregates used in commercial production of concrete. The coarse aggregate has a maximum size of $20 \mathrm{~mm}$. Its specific gravity and water absorption were measured to be 2.61 and $1.01 \%$, respectively. The fine aggregate has a maximum size of $5 \mathrm{~mm}$. Its specific gravity, water absorption and fineness modulus were measured to be $2.52,1.89 \%$ and 2.68 , respectively. Sieve analysis verified that the grading curves of the coarse and fine aggregates were within the allowable limits stipulated in British Standard BS 882: 1992 [11].

\section{Experimental Program and Method}

In this study, a total of 9 nos. high-flowability concrete mixes were produced for testing, as listed in Table 1. The $\mathrm{W} / \mathrm{C}$ ratio was varied amongst $0.40,0.50$ and 0.60 while the LF content by volume of concrete was varied amongst $0 \%$, $4 \%$ and $8 \%$. In all the concrete mixes, the powder paste volume was fixed at $34 \%$. When LF was added, the cement paste volume was reduced but the $\mathrm{W} / \mathrm{C}$ ratio was kept constant. Concrete with flowable property was investigated in the experimental program for the reason that LF is in general conducive to the production of high-workability and/or pumpable concrete mixes. It is noteworthy that the production of a flowable concrete using just a cement paste volume of $26 \%$ is not easy. Nevertheless, its low cement content renders the concrete to have small carbon footprint, which is attractive from sustainability viewpoint.

Table 1. Mix proportions of concrete specimens.

\begin{tabular}{|c|c|c|c|c|c|c|}
\hline Mix no. & W/C ratio & LF volume, \% & Cement paste volume, $\%$ & Water content, $\mathrm{kg} / \mathrm{m}^{3}$ & Cement content, $\mathrm{kg} / \mathrm{m}^{3}$ & LF content, $\mathrm{kg} / \mathrm{m}^{3}$ \\
\hline 1 & & 0 & 34 & 188 & 470 & 0 \\
\hline 2 & 0.4 & 4 & 30 & 166 & 415 & 106 \\
\hline 3 & & 8 & 26 & 144 & 359 & 211 \\
\hline 4 & & 0 & 34 & 207 & 413 & 0 \\
\hline 5 & 0.5 & 4 & 30 & 182 & 364 & 106 \\
\hline 6 & & 8 & 26 & 158 & 315 & 211 \\
\hline 7 & & 0 & 34 & 221 & 368 & 0 \\
\hline 8 & 0.6 & 4 & 30 & 195 & 325 & 106 \\
\hline 9 & & 8 & 26 & 169 & 281 & 211 \\
\hline
\end{tabular}

With the powder paste volume fixed, the aggregate volume was also fixed. Moreover, the fine to total aggregate ratio was fixed at 0.4 . In each concrete mix, the fine aggregate content, $10 \mathrm{~mm}$ aggregate content and $20 \mathrm{~mm}$ aggregate content were calculated as 672,504 and $504 \mathrm{~kg} / \mathrm{m}^{3}$, respectively. As in usual practice for the production of flowable concrete, a polycarboxylate-based superplasticizer (SP) in aqueous solution form was added to each concrete mix. The SP was added to the concrete mix in small increments until a slump of at least $200 \mathrm{~mm}$ and a flow of at least $500 \mathrm{~mm}$ were achieved. Notwithstanding the achievement of good workability, no problem of segregation of concrete was observed.

Each concrete mix was tested for its permeability in terms of water penetration depth. Three $150 \mathrm{~mm}$ cube specimens were cast from each concrete mix for testing. The cube specimens were demoulded at one day after casting and then water cured at a temperature of $27 \pm 2^{\circ} \mathrm{C}$ until the age of 28 days. The testing procedure for measuring the penetration depth was carried out in accordance with BS EN 12390-8:
2009 [12]. During the test, a water pressure of $500 \pm 50 \mathrm{kPa}$ was applied to the bottom moulded face of each cube specimen. After 72 hours, the specimens were removed from the apparatus and then each specimen was split into two halves to measure the penetration depth. The penetration depth result is taken as the average penetration depths of the three cube specimens cast from the same batch of concrete and tested at the same time. Based on the experimentally obtained penetration depth, the permeability coefficient may be derived. According to the modified Valenta equation [13], the permeability coefficient can be computed using the equation: $K=0.5 d^{2} v / t h$, where $K$ is the permeability coefficient, $d$ is the penetration depth, $v$ is the permeable porosity, $t$ is the test time and $h$ is the hydrostatic head applied. In this study, the test time $t$ is taken as 259,200 seconds ( 72 hours) and the hydrostatic head applied $h$ is taken as $50 \mathrm{~m}(500 \mathrm{kPa})$. The permeability coefficient results so obtained are presented in the fourth column of Table 2 .

Testing of permeable porosity was also conducted. For each 
concrete mix, three $100 \mathrm{~mm}$ cube specimens cast from the same batch of concrete were tested in accordance with the American Standard ASTM C642-06 [14]. Basically, after water curing until the age of 28 days, each specimen was oven dried to measure its oven-dry mass, then immersed in water and boiled to measure its saturated mass, and finally immersed in water to measure its apparent mass in water. The permeable porosity so determined is the volume of pores that can be filled by water, expressed as a percentage or fraction of the volume of concrete. The permeable porosity result is taken as the average of the three specimens cast from the same batch of concrete and tested at the same time.

The cube compressive strengths were measured by casting three $150 \mathrm{~mm}$ cubes from the concrete, removing the moulds one day after casting, applying water curing at a temperature of $27 \pm 2^{\circ} \mathrm{C}$, and testing the cubes at the age of 28 days, in accordance with BS EN 12390-3: 2009 [15]. The cube strength result is taken as the average cube compressive strengths of the three cubes cast from the same batch of concrete and tested at the same time.

\section{Experimental Results}

The penetration depth, permeable porosity, permeability coefficient, 28-day cube strength results of the concrete mixes are presented in the second to fifth columns of Table 2, respectively. The water penetration depth is plotted against the $\mathrm{W} / \mathrm{C}$ ratio in Fig. 1. It is evident that at the same $\mathrm{W} / \mathrm{C}$ ratio, the water penetration depth decreased as the LF volume increased and such effect of LF was generally larger at higher $\mathrm{W} / \mathrm{C}$ ratio.

Table 2. Experimental results.

\begin{tabular}{|c|c|c|c|c|}
\hline Mix no. & Penetration depth, m & Permeable porosity, \% & Permeability coefficient, $10^{-11} \mathrm{~m} / \mathrm{s}$ & 28-day cube strength, MPa \\
\hline 1 & 0.0310 & 10.1 & 0.374 & 74.8 \\
\hline 2 & 0.0195 & 8.4 & 0.123 & 80.5 \\
\hline 3 & 0.0185 & 7.8 & 0.103 & 85.1 \\
\hline 4 & 0.0560 & 14.3 & 1.730 & 56.0 \\
\hline 5 & 0.0265 & 10.4 & 0.282 & 62.0 \\
\hline 6 & 0.0230 & 8.8 & 0.180 & 68.7 \\
\hline 7 & 0.0750 & 16.2 & 3.516 & 44.3 \\
\hline 8 & 0.0360 & 12.5 & 0.625 & 49.2 \\
\hline 9 & 0.0290 & 10.9 & 0.354 & 51.5 \\
\hline
\end{tabular}

From the test results, it is evident that with LF added as cement paste replacement, the penetration depth would increase more slowly with the $\mathrm{W} / \mathrm{C}$ ratio. That is to say, the addition of LF as cement paste replacement would render the permeability less sensitive to the $\mathrm{W} / \mathrm{C}$ ratio. For instance, with no LF added, the penetration depth would dramatically increase by $80.6 \%$ and $141.9 \%$ when the $\mathrm{W} / \mathrm{C}$ ratio is increased from 0.40 to 0.50 and 0.60 , respectively. With $4 \% \mathrm{LF}$ added, the penetration depth would only increase by $35.9 \%$ and $84.6 \%$ when the W/C ratio is increased from 0.40 to 0.50 and 0.60 , respectively. Likewise, with $8 \%$ LF added, the penetration depth would only increase by $24.3 \%$ and $56.8 \%$ when the $\mathrm{W} / \mathrm{C}$ ratio is increased from 0.40 to 0.50 and 0.60 , respectively.

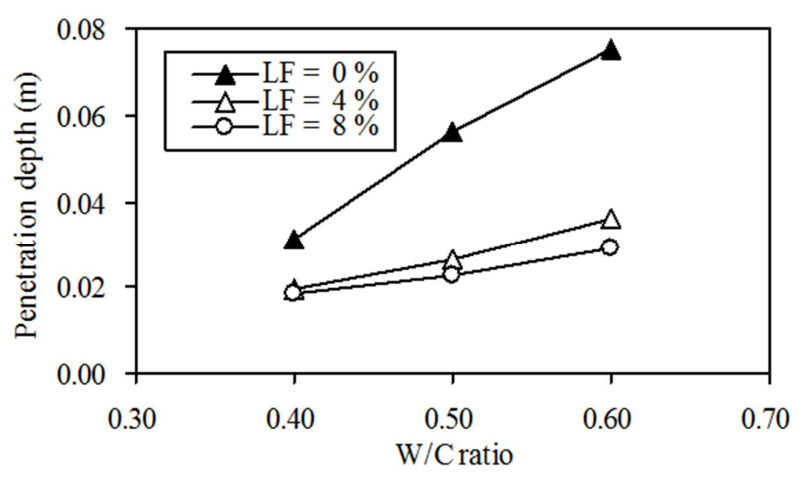

Figure 1. Penetration depth versus $W / C$ ratio.

In the following, the concurrently achieved permeability and strength performance is examined. It is found that the addition of LF as cement paste replacement without changing the W/C ratio not only decreases the penetration depth, but also increases the strength of the concrete, as shown in last column in Table 2. If a higher strength is not really needed, the opportunity may be taken to adjust the $\mathrm{W} / \mathrm{C}$ ratio upwards to improve the workability and further reduce the cement content. For assessing the effectiveness of adding LF in reducing the permeability on an equal strength basis, the penetration depth is plotted against the average 28-day cube compressive strength for different LF volumes in Fig. 2. It is seen that even with the $\mathrm{W} / \mathrm{C}$ ratio adjusted upwards to keep the strength of concrete at the same level, the addition of LF to replace an equal volume of cement paste would still effectively reduce the permeability of the concrete. This illustrates the beneficial effects of LF with respect to both permeability and strength enhancement.

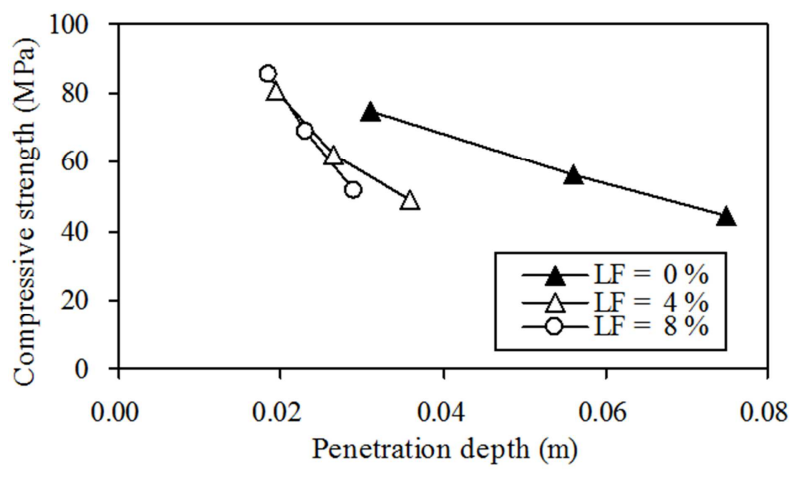

Figure 2. Compressive strength versus penetration depth.

The compressive strength is plotted against the permeable porosity in Fig. 3. The graphical results show that the addition of LF would shift the compressive strength-permeable 
porosity curve to the left and moderately upwards. That is to say, addition of the LF could at the same strength requirement decrease remarkably the permeable porosity. And by adding LF, the compressive strength is moderately increased. This illustrates the beneficial effects of LF with respect to both permeable porosity and strength enhancement. The addition of LF increases the strength partially through reducing the permeable porosity of concrete. Nevertheless, by drawing imaginary horizontal lines across Fig. 3, the reduction in permeable porosity on an equal strength basis due to incorporation of LF may be apparently observed.

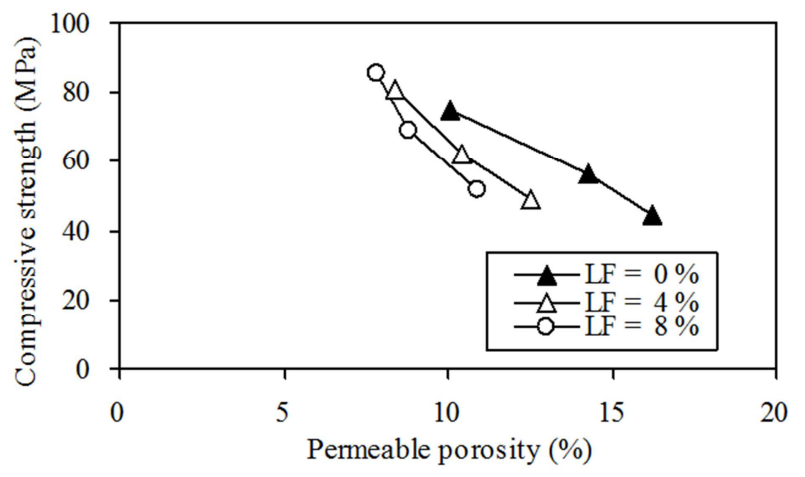

Figure 3. Compressive strength versus permeable porosity.

Likewise, the concurrently attained compressive strength and permeability coefficient is plotted in Fig. 4. It is seen that by adding LF, the compressive strength-permeability coefficient curves are shifted in the similar manner to that in Fig. 2. On an equal strength basis, the addition of $4 \%$ LF could significantly decrease the permeability coefficient, while further addition of LF to $8 \%$ could only marginally decrease the permeability coefficient.

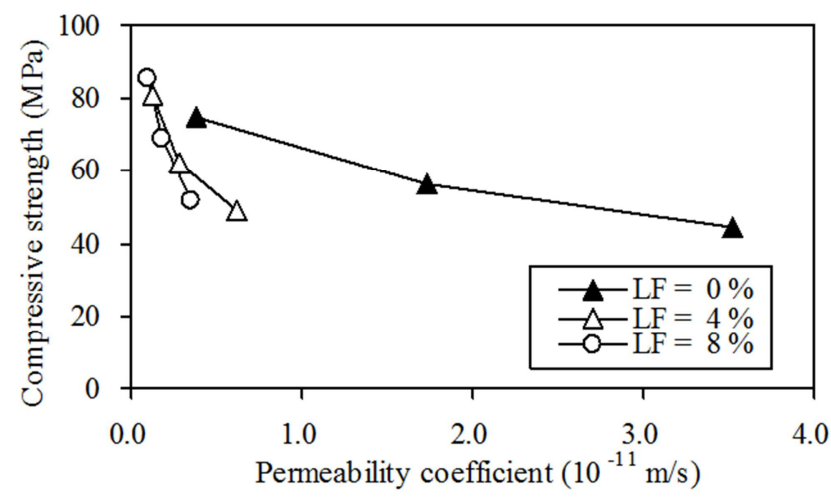

Figure 4. Compressive strength versus permeability coefficient.

\section{Relationship Among Penetration Depth, Permeable Porosity, and Permeability Coefficient}

To study the relationship between the penetration and the permeability, the penetration depth is plotted against the permeable porosity in Fig. 5, where a best-fit curve derived by regression analysis is also plotted alongside the data points to illustrate the variation trend of the data points. The regression analysis yielded a linear relationship between the penetration depth and the permeable porosity with $R^{2}=0.932$ (the formula so derived is printed in the figure for easy reference). Such a high $R^{2}$ value indicates that the permeability of concrete is strongly related to the permeable porosity.

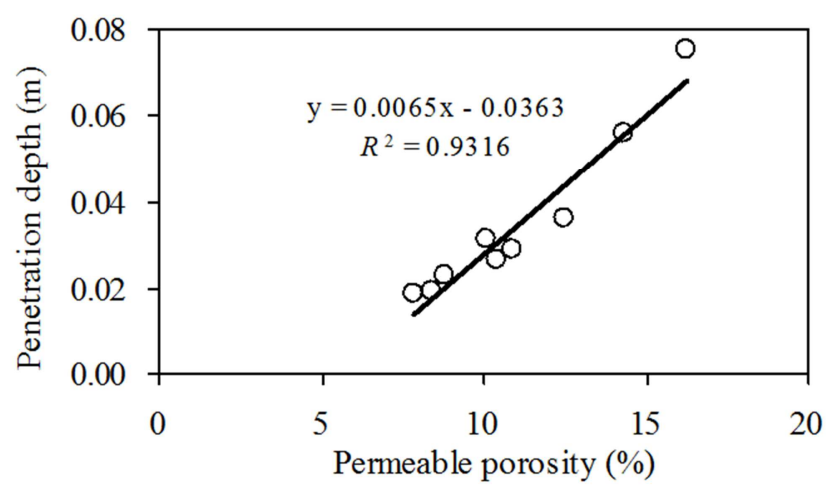

Figure 5. Penetration depth versus permeable porosity.

Likewise, to study the relationship between the penetration depth and the permeability coefficient, the penetration depth is plotted against the permeable porosity in Fig. 6, where a best-fit curve derived by regression analysis is also plotted alongside the data points. The regression analysis yielded a exponential relationship between the penetration depth and the permeability coefficient with $R^{2}=0.998$ (the formula so derived is printed in the figure for easy reference). The very high $R^{2}$ value confirms the excellent correlation between penetration depth and permeability coefficient.

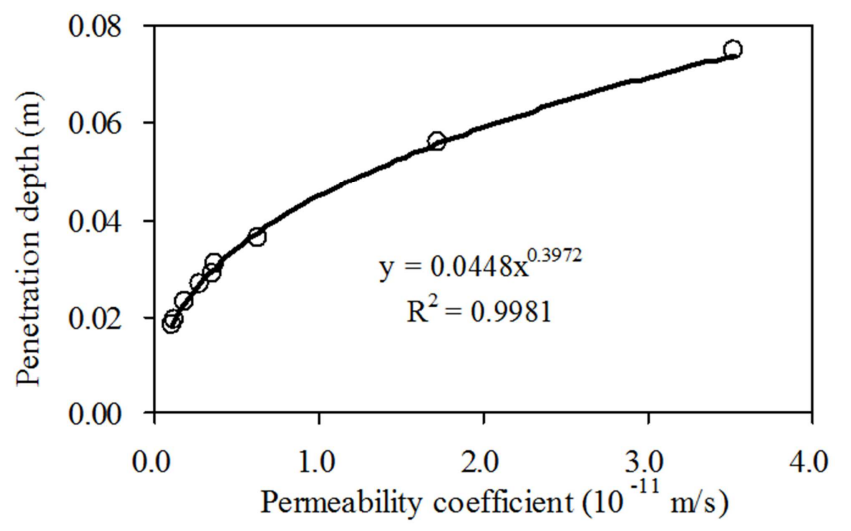

Figure 6. Penetration depth versus permeability coefficient.

To study the relationship between permeability coefficient and permeable porosity, they are plotted graphically in Fig. 7. Inspection of the trend of data reveals that as the permeable porosity increases to beyond about $10 \%$, the permeability coefficient would increase very rapidly with the permeable porosity. Regression analysis between these two quantities is conducted. The regression formula is found to be an exponential function, and the coefficient of correlation obtained is as high as 0.972 . Therefore, the permeability coefficient of concrete is strongly related to the permeable porosity in an exponential manner. 


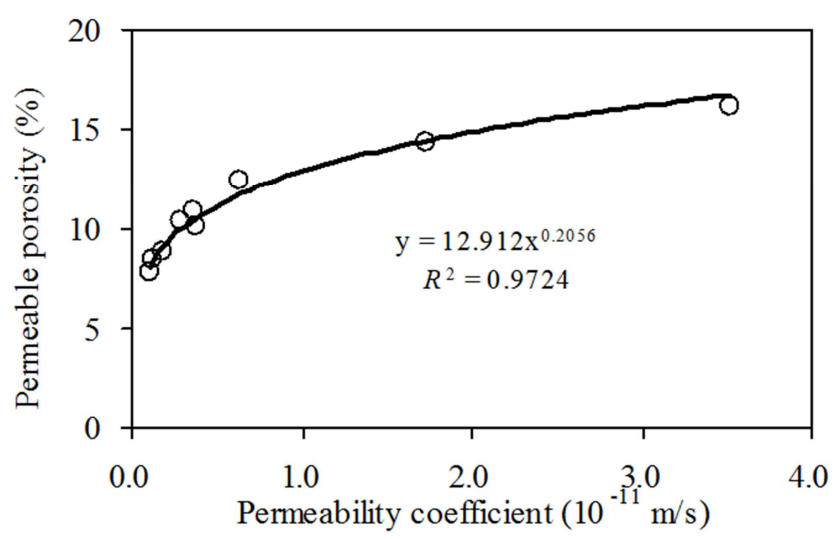

Figure 7. Permeable porosity versus permeability coefficient.

\section{Discussions}

As discussed in the Introduction part, the conventional use of LF is basically to replace either part of the cement or part of the fine aggregate. For the former strategy, although the cement clinker consumption and the hydration heat of concrete can indeed be significantly reduced [16], the addition of LF as cement replacement up to $20 \%$ may increase the gas permeability and permeability, which would impaired the durability [17]. Also, with the cement replaced by LF, the water/ (cement + LF) ratio actually need to be lowered to compensate the loss in strength [18-19]. For the latter strategy, although the addition of LF as aggregate replacement may decrease the permeability [7], this strategy would not help to reduce the cement clinker consumption and carbon footprint of the concrete.

In contrast to the above traditional strategies, using LF to replace part of cement paste as reported in this study and advocated by the authors can effectively benefit the water impermeability and durability as well as sustainability at the same time. As the permeability coefficient is strongly correlated to the permeable porosity, the effect of addition of LF on durability is likely through the effects on permeable porosity. To enable wider use of LF in the production of various high-performance concrete, further systematic research on other properties and performance attributes of fresh and hardened concrete mixes incorporating LF is recommended.

\section{Conclusion}

A total of 9 nos. concrete mixes at the same powder paste ratio and various limestone fines (LF) contents and $\mathrm{W} / \mathrm{C}$ ratios have been produced for permeability and strength measurement to verify the effectiveness of adding LF as cement paste replacement on durability improvement. The experimental results have shown that, at a constant $\mathrm{W} / \mathrm{C}$ ratio, the addition of LF as cement paste replacement would significantly increase the compressive strength and substantially reduce the permeability. Even with the $\mathrm{W} / \mathrm{C}$ ratio adjusted upwards to keep the strength constant, such usage of LF could still effectively reduce the permeability for durability improvement.

From the experimental results, it has been found that the addition of LF to replace cement paste could also reduce the permeable porosity of concrete significantly. This indicates that the LF added, which has similar fineness to cement particles, is capable of filling into the pores in concrete to reduce the porosity. Regression analysis has demonstrated that the penetration depth is strongly correlated to the permeable porosity in an approximately linear manner. Thus, the reductions in penetration depth may be attributed to the corresponding reduction in permeable porosity due to addition of LF. Besides, the permeability coefficient is strongly correlated to the permeable porosity in an exponential manner. When the permeable porosity increases to higher than about $10 \%$, the permeability coefficient increases very rapidly. Further research on the properties and performance attributes of concrete mixes incorporating LF is recommended.

\section{Acknowledgements}

The work described in this paper was supported by the grant $\mathrm{PhD}$ Start-up Fund of Natural Science Foundation of Guangdong Province, China (Project No. 2014A030310273).

\section{References}

[1] British Standards Institution, BS EN 197-1: 2011, Cement Part 1: Composition, specifications and conformity criteria for common cements, BSI, London, UK; 2011.

[2] L. G. Li, A. K. H. Kwan, "Adding limestone fines as cementitious paste replacement to improve tensile strength, stiffness and durability of concrete" Cem. Con. Comp. vol. 60 (6), 2015, pp. 17-24.

[3] G. Fares, "Effect of slump cone orientation on the slump flow time (T50) and stability of sustainable self-compacting concrete containing limestone filler," Constr. Build. Mater. vol. 77, 2015, pp. 145-153.

[4] S. Kenai, B. Menadi, A. Attar, and J. Khatib, "Effect of crushed limestone fines on strength of mortar and durability of concrete," Proceedings, International Conference on Construction and Building Technology (ICCBT), Kuala Lumpur, Malaysia, 2008, pp. 205-216.

[5] Z. Guemmadi, H. Houari, and B. Toumi, "Behaviour of limestone sand based concrete with variable filler content," Proceedings, Annual Conference - Canadian Society for Civil Engineering, vol. 2, 2008, pp. 1232-1242.

[6] C. Aquino, M. Inoue, H. Miura, M. Mizuta, and T. Okamoto, "The effects of limestone aggregate on concrete properties," Constr. Build. Mater. vol. 24 (12), 2010, pp. 2363-2368.

[7] B. Menadi, S. Kenai, J. Khatib, and A. Aït-Mokhtar, "Strength and durability of concrete incorporating crushed limestone sand," Constr. Build. Mater. vol. 23 (2), 2009, pp. 625-633.

[8] A. M. Diab, A. E. M. Abd Elmoaty, A. A. Aly, "Long term study of mechanical properties, durability and environmental impact of limestone cement concrete," Alexandria Engineering Journal, In Press, Corrected Proof, Available online 19 February 2016. 
[9] A. M. Diab, I. A. Mohamed, A. A. Aliabdo, "Impact of organic carbon on hardened properties and durability of limestone cement concrete," Constr. Build. Mater. vol. 102, 2016, pp. 688-698.

[10] British Standards Institution, BS 12: 1996, Specifications for Portland cement, BSI, London, UK; 1996.

[11] British Standards Institution, BS 882: 1992, Specification for aggregates from natural sources for concrete. BSI, London, UK; 1992.

[12] British Standards Institution, BS EN 12390-8: 2009, Testing hardened concrete - Part 8: Depth of penetration of water under pressure. BSI, London, UK; 2009.

[13] V. S. Ramachandran, and J. J. Beaudoin, Handbook of Analytical Techniques in Concrete Science and Technology: Principles, Techniques and Applications. William Andrew, Norwich, UK; 2000, pp. 709.

[14] American Society for Testing and Materials, ASTM C642-06, Standard test method for density, absorption, and voids in hardened concrete. ASTM International, USA; 2006.
[15] British Standards Institution, BS EN 12390-3: 2009, Testing hardened concrete - Part 3: Compressive strength of test specimens. BSI, London, UK; 2009.

[16] A. M. Poppe, and G. De Schutter, "Cement hydration in the presence of high filler contents," Cem. Con. Res. vol. 35 (12), 2005, pp. 2290-2299.

[17] S. Tsivilis, J. Tsantilas, G. Kakali, E. Chaniotakis, and A. Sakellariou, "The permeability of Portland limestone cement concrete,” Cem. Con. Res. vol. 33 (9), 2003, pp. 1465-1471.

[18] D. P. Bentz, E. F. Irassar, B. E. Bucher, and W. J. Weiss, "Limestone fillers conserve cement: Part 1: An analysis based on Powers' model," Con. Int. vol. 31 (11), 2009, pp. 41-46.

[19] D. P. Bentz, E. F. Irassar, B. E. Bucher, and W. J. Weiss, "Limestone fillers conserve cement: Part 2: Durability issues and the effects of limestone fineness on mixtures," Con. Int. vol. 31 (12), 2009, pp. 35-39. 